\title{
Editorial
}

\section{Second opinion in plastic surgery}

$t$ is not at all uncommon to encounter a patient who has come to us for a second opinion. He/she may be seeking a preoperative consultation to understand his/ her options or even a postoperative one to see how his/ her surgeon has performed. In both the instances, he/she is a new patient for us and it is vital that we do justice to the trust the patient has bestowed upon us. But, while doing so, do we need to be concerned only about this patient or do we have to protect the interest of our fellow colleague who has offered the first opinion or performed the surgery? If the best interest of the patient has been served by our previous colleague then this is not a difficult question to answer, but if that is not the case, then what do we do? How do we disagree with a fellow colleague without being disagreeable?

One of the many wonderful things about plastic surgery is that there is rarely one way to approach a patient's concern or treat a problem. We take pride in skinning the cat differently and then invariably boasting about our technique in meetings and conferences. Plastic surgeons with different experiences, different trainings and, sometimes, different geographic locations and cultural backgrounds may treat certain cosmetic and reconstructive concerns very differently from the way we do. For this reason, patients considering plastic surgery often get second opinions and end up more confused rather than enlightened. A second opinion should be encouraged and is very valuable particularly if we can see some residual disease/deformities or preempt some donorsite morbidities.

During a second opinion, a patient is simply asking us what we intend to offer him/her based on our past experience with a similar disease or deformity. Besides encouragement and honesty, which every patient has a right to get from a

\begin{tabular}{|l|l|}
\hline \multicolumn{3}{|c|}{ Access this article online } \\
\hline Quick Response Code: & Website: \\
\hline & www.ijps.org \\
\cline { 2 - 2 } & DOI: \\
\hline
\end{tabular}

consulting surgeon, the patient has come to get the best information possible so as to make the most educated decision.

The first thing in every consultation and, particularly, in a consultation for a second opinion is to hear what all the patient has to say. This may not always be brief, and may not always be true. Patients often do not reveal that the consultation is for a second opinion either because they do not want our judgment to be biased or because they do not like to be seen as one who does not trust a doctor who has seen them before. So, the very next thing we need to do is to reassure them that there certainly is nothing wrong with getting a second, third or fourth opinion. That is their right and particularly because they are spending their time and their money. Even if they reveal the contents of the first consultation with our fellow colleague, it is surely not to prejudice our thoughts and recommendations and they are not trying to measure or compare us with someone else. We have to believe that they are seeking an unbiased opinion.

In secondary consultations, it is advisable not to engage in a discussion of what the other plastic surgeon said and ask what he or she thinks about their recommendations. This is particularly important when the recommendations are different from that of ours. Personalities, ego and professional jealousies can all enter into what is subsequently said. One is unlikely to separate out the facts from the emotion in that scenario. We should ask specifically why those recommendations are best and what the downsides might be. If we know of other options that may be different, we must make the patient aware of them and then tell them why the option we have selected is better. We should always listen and take notes and photographs. We will need them in the future if the patient comes back to us. His/her doubts and apprehensions and our responses should all be noted for future references.

The discussions should be honest, enriching and illuminating to the patient and never derogatory towards a fellow colleague. His/her doctor's lack of knowledge or experience is not what the patient intends to discuss, and if he/she does, it is perfectly appropriate to abruptly end this line of

Indian Journal of Plastic Surgery January-April 2011 Vol 44 Issue 1 
conservation with a polite reminder that such issues are not within the ambit of discussion. I know of a senior Professor of Surgery who had a plaque on his table that read "I discuss diseases not doctors".

If the patient has been encouraged by his doctor to seek our opinion, then our responsibility redoubles; not only have we to satisfy the patient but also do justice to the trust our colleague has imposed upon us. We should call him/her up or write a note of thanks and explain our line of treatment.

But, what if the patient has had a truly bad experience? There are two strikingly different situations and require two diametrically opposite responses. If we can see that the problem is because of a known complication, like a fistula after a hypospadias repair or a scar hypertrophy after scar revision, we must reassure the patient that it was a very rare occurrence and an episode of just bad luck for both the patient and his/her doctor. If, now, we vouch for the competency of our unfortunate colleague instead of going for the proverbial kill, we exhibit exemplary discipline and courage in our practice, and this usually goes down very well with patients. But, if the patient has been truly short changed, particularly by someone not qualified to do the job, masquerading as a Plastic Surgeon and trying to poach into the sacred territory of Plastic Surgery, we should make sure that the patient does not return to the same doctor. The interest of the patient still remains our foremost concern and we have to offer a result that should speak volumes of our training and skill.
Like in any other speciality, in Plastic Surgery too the cost of the procedure is important and definitely one of the vital factors in making a final decision. We should never... and I repeat never...make a consultation appear as if we are touting the best price. If market forces are going to govern the destiny of the patient, we should have nothing to do in the bidding process. A second opinion is not an opportunity to outbid a colleague. This does not sit well with most plastic surgeons and casts a negative overtone to the whole consultation. Price bartering, unlike some retail industries, does not usually work well in plastic surgery. It is not only inappropriate but is also not that effective. This is not the time to begin price discussions. If everything else is equal and plastic surgeons have different prices, then a smart patient very tactfully asks the question - why? This is the time to offer a good reason - better infrastructure, safer surgical facilities, no hidden costs, etc.

Remember authenticity is the silver bullet and competence, communication skills and compassion are vital adjuvants. An honest individuality is the most magnetic of qualities a patient is seeking in a Plastic Surgeon. And, as I have learned from Dr. Tom Biggs, Editor in Chief of Aesthetic Plastic Surgery, "talking with the patient" is far better than "talking to the patient".

\section{Surajit Bhattacharya} Editor, IJPS, Sr. Consultant Plastic Surgery, Sahara Hospital, Lucknow, India. E-mail: surajitb@sanchanet.in

Announcement

\section{“QUICK RESPONSE CODE" LINK FOR FULL TEXT ARTICLES}

The journal issue has a unique new feature for reaching to the journal's website without typing a single letter. Each article on its first page has a "Quick Response Code". Using any mobile or other hand-held device with camera and GPRS/other internet source, one can reach to the full text of that particular article on the journal's website. Start a QR-code reading software (see list of free applications from http://tinyurl.com/yzlh2tc) and point the camera to the QR-code printed in the journal. It will automatically take you to the HTML full text of that article. One can also use a desktop or laptop with web camera for similar functionality. See http://tinyurl.com/2bw7fn3 or http://tinyurl.com/3ysr3me for the free applications. 